\title{
Patterns of increasing $\beta$-agonist use and the risk of fatal or near-fatal asthma
}

\author{
S. Suissa*†, L. Blais*, P. Ernst*†
}

Patterns of increasing $\beta$-agonist use and the risk of fatal or near-fatal asthma. OERS Journals Ltd 1994.

ABSTRACT: The association between the use of inhaled $\beta$-agonists by metereddose inhaler and the risk of fatal or near-fatal asthma has been demonstrated. It shows that asthmatics who use one canister of $\beta$-agonist per month more than the number used by other similar asthmatics have twice the risk of fatal or near-fatal asthma. The present investigation assesses the magnitude of this excess risk when an asthmatic increases his/her own monthly use of inhaled $\beta$-agonists over time.

From a previous nested case-control study of 129 deaths and near-deaths from asthma (cases) and 655 controls from a cohort of 12,301 asthmatics, the subset using at least 12 inhalers during the 12 month study period was identified ( 97 cases and 258 controls). A profile score, ranging $0-11$, was formed to quantify the patterns of $\beta$-agonist use over time for each subject, covering the entire spectrum extending from decreasing to increasing use.

The relative risk was 15.2 (95\% confidence interval (CI) 2.4-96.2) per unit increase of the profile score in subjects with a pattern of increasing $\beta$-agonist use (profile score of 6.5 or more), but this relative risk was only 1.5 (95\% CI 0.8-2.6) per unit when the profile score was less than 6.5 (non-increasing use). This relative risk was independent of the risk associated with the total quantity of $\beta$-agonist use in the 12 month period, which remained around $1.6(95 \%$ CI 1.3-2.0) per inhaler per month.

We conclude that above and beyond the quantity of $\beta$-agonist used during a one year period, a pattern of increasing use of $\beta$-agonist inhalers over that period is a major predictive factor of unfavourable outcomes in asthma. Any trend, over a six month span, of a doubling in the monthly use of $\beta$-agonists, or, alternatively, of an increase by one canister in this monthly use, should be regarded as a serious warning sign of an impending life-threatening attack of asthma. Eur Respir J., 1994, 1602-1609.

The possible association between the use of $\beta$-agonist medications and asthma mortality was first suggested in the 1960s [1]. Further studies of this association have either supported [2], or contradicted [3], this finding. A subsequent study imputed this association to a specific drug formulation, isoproterenol, at high concentrations [4]. All of these studies, however, were based on ecological analyses, which cannot be conclusive since they fail to link exposure to the medication with the subjects experiencing the adverse outcomes. Recently, after the introduction of selective $\beta$-agonists, three case-control studies from New-Zealand [5-7] reported an increased risk of asthma death in subjects using one $\beta$-agonist, fenoterol, but not another, salbutamol. This unexpected finding constituted the basis for the Saskatchewan Asthma Epidemiology Project, from which we reported an elevated risk of fatal and near-fatal asthma for all inhaled $\beta$-agonists by metered-dose inhaler (MDI), including salbutamol and fenoterol [8]. Although the risk for fenoterol was higher than that of salbutamol in terms of the absolute number of canisters used, there was no difference between the two risks when adjusted for the higher dose for fenoterol (200 vs $100 \mu \mathrm{g} \cdot$ puff $\left.^{-1}\right)$.
*Dept of Epidemiology and Biostatistics and the Pharmacoepidemiology Research Unit, and $\dagger$ Dept of Medicine, Montreal General Hospital, McGill University, Montreal, Quebec, Canada.

Correspondence: S. Suissa, Dept of Epidemiology and Biostatistics, McGill University, 1020 Pine Avenue West, Montreal Quebec, Canada H3A 1A2

Keywords: Asthma drug therapy asthma morbidity and mortality drug utilization patterns pharmacoepidemiology risk markers

Received: January 191994 Accepted after revision June 281994

This study is supported by a grant from Boehringer-Ingelheim Pharmaceuticals, Canada, Ltd. SS and PE are research scholars of the Fonds de la recherche en santé du Québec (FRSQ). LB is the recipient of a doctoral scholarship from the National Health and Research Development Program (NHRDP) of Canada. The McGill Pharmacoepidemiology Research Unit is supported by an infrastructure Equipe grant from the FRSQ.
The risk of these adverse events was found to increase about twofold for each additional canister of $\beta$-agonist by MDI used per month during a one year period. This relative risk was based on comparing groups of asthmatics who differ in their use of $\beta$-agonist by one canister per month. The measure of $\beta$-agonist use employed in the analysis was the total number of canisters dispensed over the 12 month period preceding the adverse event for the cases and corresponding date for the matched controls, expressed as the average monthly use over the one year span. The result of this study, based on contrasting different asthma patients with similar characteristics, has been interpreted as a two fold increase in risk if a patient increases his/her own use of $\beta$-agonists by one canister per month. For example, an asthmatic patient who increases his/her use of $\beta$-agonists gradually from one canister per month to three is believed, from the previous study, to increase his/her risk roughly fourfold. This interpretation is based on a comparison between patients dispensed different amounts of $\beta$-agonists and not within patients who increase their own $\beta$-agonist use over time, although it is applied to the latter. Whilst this interpretation may be valid, it must be 
verified using another approach, which addresses, specifically, the effects of increases in $\beta$-agonist use over time by individual study subjects.

In this paper, we evaluate whether, and to what extent, a pattern of increasing use of inhaled $\beta$-agonists by MDI, within individual patients over a one year time span, is associated with the risk of fatal and near-fatal asthma.

\section{Methods}

The cohort has been described in detail previously [8]. It consisted of the 12,301 residents of Saskatchewan, aged 5-54 yrs, who in the span 1978-1987 had been dispensed 10 or more prescriptions for asthma drugs. These were identified from the computerized databases resulting from the comprehensive Saskatchewan health insurance plan. The date of entry into the cohort is the last of the dates of the 10th prescription, January 1, 1980, or the 5th birthday. The exit date is the first of the dates of death, emigration from the province, April 30, 1987, or the 55th birthday. In this cohort, 180 deaths were identified from the vital statistics component of the Saskatchewan Health databases. For all deceased subjects, we obtained the available death certificate, autopsy report, coroner's report and hospital discharge summary form. These were classified independently by three physicians experienced in the treatment of asthma, in terms of their relation to asthma, leading to 44 fatal asthma cases. In addition, we identified from hospital databases 964 subjects with potential near-fatal asthma. Of these, the hospital records permitted 85 cases of near-fatal asthma to be identified, defined by hypercarbia, i.e. arterial partial pressure of carbon dioxide above $6.0 \mathrm{kPa}(45$ $\mathrm{mmHg}$ ), or nonelective intubation during an asthma attack.

Up to eight controls from the cohort were matched to each case by age, social assistance, area of residence, the fact of prior asthma hospitalization and calendar time (index date). Thus, the study population consisted of a nested case-control sample of 129 cases (44 asthma deaths, 85 asthma near-deaths) and 655 matched controls, selected from a cohort of 12,301 asthmatics. For each case and matched control, all prescribed canisters of inhaled $\beta$-agonist by MDI dispensed by a pharmacist in the year preceding the case adverse event date (index date) were obtained. The two principal $\beta$-agonists were salbutamol, dispensed as an MDI containing 200 inhalations of 100 $\mu \mathrm{g}$ each, and fenoterol, containing 200 inhalations of 200 $\mu \mathrm{g}$ each. Dispensed prescriptions of all other asthma, cardiovascular (including antihypertensives and diuretics), neurological and contraindicated (beta-blockers, parasympathomimetics, sedatives) drugs were also obtained. In addition, the number of asthma hospitalizations in the 2 years prior to the index date were ascertained, since this appears to be a major risk factor for fatal asthma [9].

To assess the patterns of $\beta$-agonist use, we had to restrict the study population to subjects who had been dispensed at least some inhaled $\beta$-agonist in the one year time window preceding the index date. The cut-off value for this restriction was selected with the intention of providing an acceptable balance between quantifiable patterns of use and a sufficient number of subjects needed to yield precise statistical analyses. Indeed, a "pattern" would be impossible to quantify for a subject using only one or two canisters during a one year span, while it can be quantified precisely if the patient used a large, e.g. 25-30, number of canisters. The number of subjects using 25-30 canisters per year, however, is too small for an acceptable statistical analysis. We therefore opted for a cut-off of 12 or more canisters of inhaled $\beta$-agonists in the one year time window preceding the index date (one per month), which confined the study population to 97 cases and 258 controls.

For each subject, we computed the monthly distribution of canisters of any of the available inhaled $\beta$-agonists (salbutamol, fenoterol, metaproterenol and terbutaline) across the 12 months preceding the index date. To summarize this distribution, we defined a profile score, which measures, for each subject, the growth profile of inhaled $\beta$-agonist use in the 12 month timespan prior to the index event date. We quantified this profile score for each subject by the area above the curve delineated by the cumulative distribution of canisters in the 12 month exposure time window. This cumulative distribution curve is simply the monthly cumulative proportion of canisters dispensed out of all canisters dispensed during that 12 month period for the subject. As a convention, the month just prior to the index date is defined as the 12th month, and the month furthest from the index date ( 12 months earlier) as the 1 st month. Thus, for the first month, the cumulative distribution is, out of all canisters for the subject during the 12 month period, the proportion dispensed on the first month, whilst for the second month it is the proportion dispensed on the first and second months combined, etc. The sum of these cumulative proportions over all 12 months results in the area under the cumulative distribution (ACD). The profile score (PS) then turns out to be simply PS=12-ACD.

This profile score may vary from 0 to 11 , with 0 on one extreme indicating that all of the canisters for the year were dispensed on the first month, i.e. 12 months before the index date, and none in the remaining 11 months; whereas, 11 indicates that all use in the year was concentrated in the single month immediately preceding the index date. In general, a profile score below 5.5 indicates decreasing $\beta$-agonist use; and above 5.5 an increasing profile; whereas, 5.5 indicates a constant regular use over the 12 month period, going from month 1 to 12 . To illustrate this measure, figure $1 \mathrm{a}-\mathrm{c}$ displays three histograms to depict the different monthly distributions of the number of canisters for three subjects in our study who have a virtually identical total number of canisters for the one year period, i.e. 27, 28 and 28. Figure $2 \mathrm{a}-\mathrm{c}$ depicts the three corresponding cumulative distributions, with the region above the curve shaded for illustration. The areas of these shaded regions yield profile scores of 4.3, 5.5 and 7.5, which reflect the decreasing, regular and increasing profiles of $\beta$-agonist use over the 12 month span, respectively, evident in figure 1 .

Although the original 129 cases were matched to the 655 controls, the restricted subgroup of 97 cases and 258 

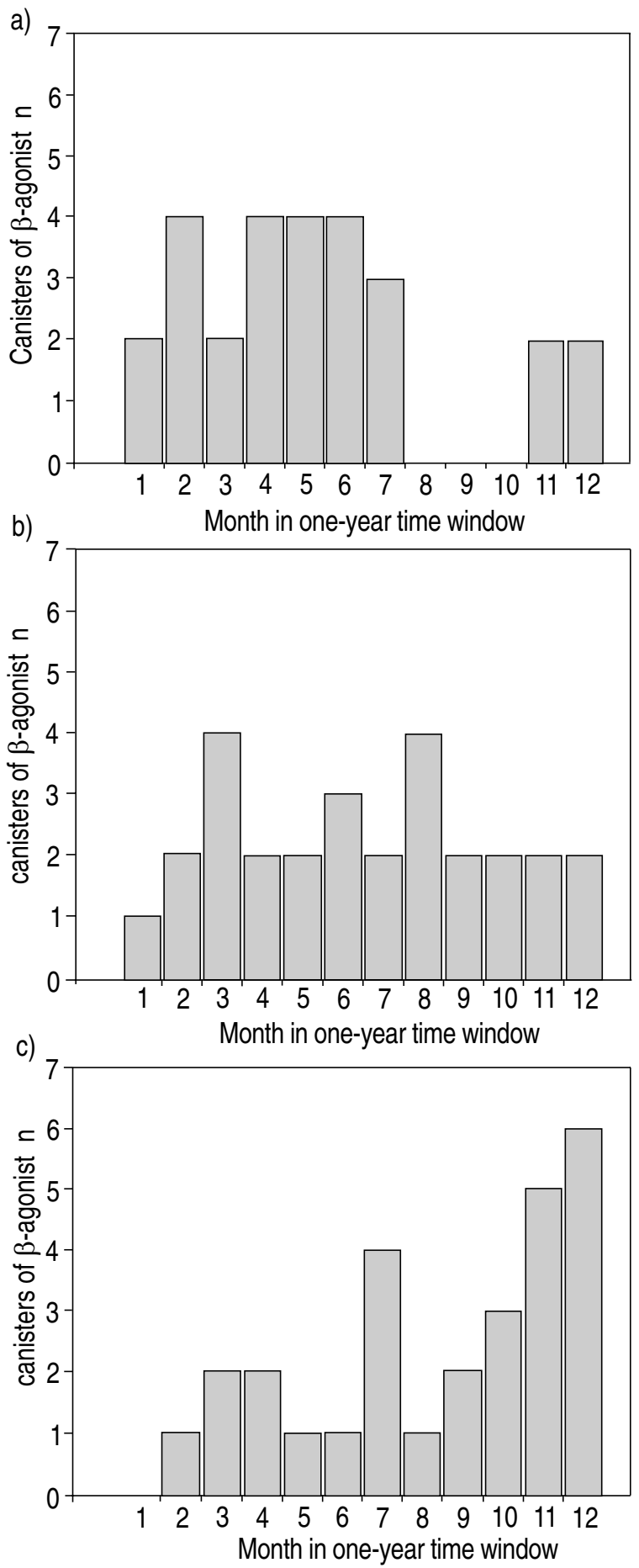

Fig. 1. - Monthly distribution of canisters of inhaled $\beta$-agonist for three study subjects, all with totals of 27 or 28 canisters for the 12 month time window. These reflect three different patterns of use: a) decreasing; b) regular; and c) increasing.

controls for the present analysis cannot be fully matched. Indeed, to conserve the matching in the analysis, we would have to eliminate 12 cases and 54 controls who have no match. Consequently, the analysis is based on unconditional logistic regression methods for unmatched data, adjusted for the matching factors if they are found to be influential. As a verification, a matched analysis using conditional logistic regression was also performed
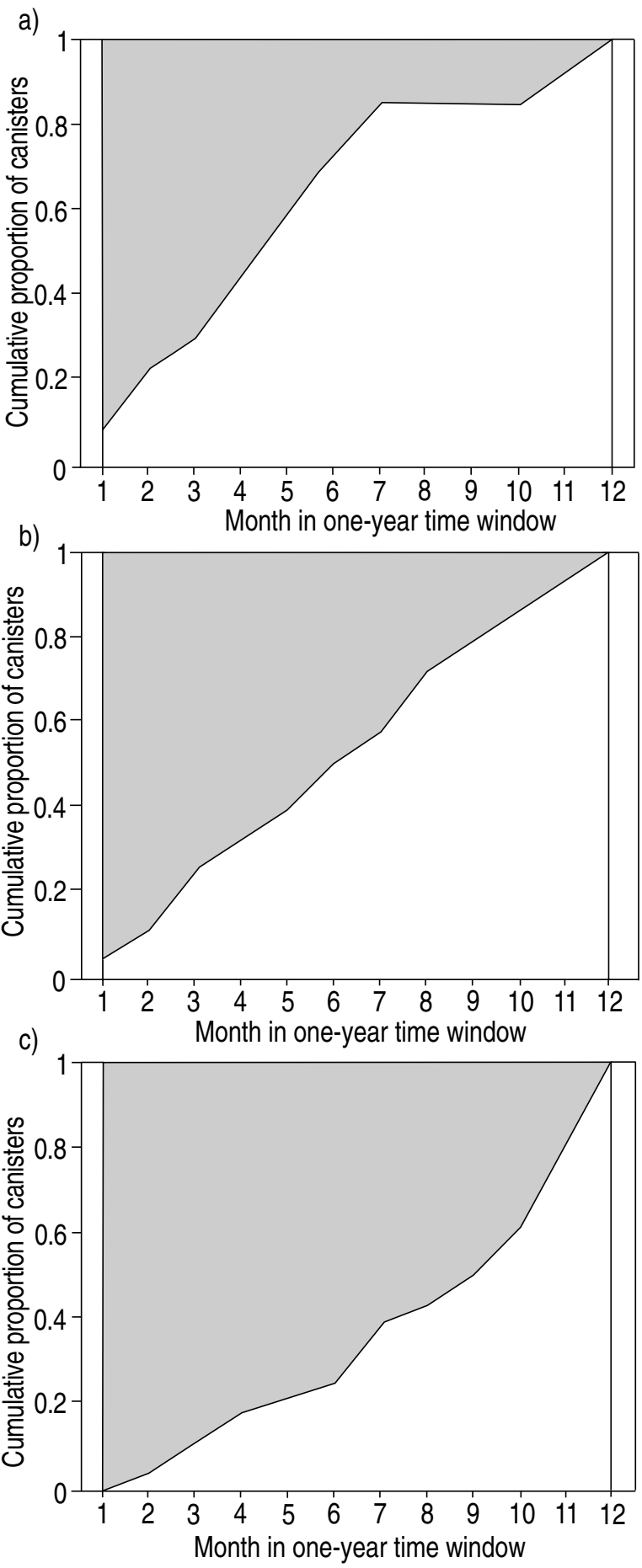

Fig. 2. - Cumulative distribution of canisters in the 12 month exposure time window for the monthly distributions of figure 1 . The profile score, ranging $0-11$, is quantified by the area of the shaded region above the curve: a) $=4.3$; b) $=5.5$; and c) $=7.5$.

on the 85 matched sets for which there were a case and at least one matched control. Lastly, although our previous results justify that the analyses be based on combining all inhaled $\beta$-agonists together, and not necessarily distinguishing individual products [8], analyses were redone separately for fenoterol and salbutamol, albeit with fewer subjects, to assess the validity of the conclusions on the entire class of inhaled $\beta$-agonists. 
Table 1. - Characteristics of study subjects

\begin{tabular}{lcc}
\hline & Cases & Controls \\
\hline Subjects n & 97 & 258 \\
Male gender \% & 56 & 57 \\
Age at index event* yrs & $29 \pm 14$ & $32 \pm 13$ \\
Asthma hospitalizations*\# n & $2.5 \pm 3.7$ & $1.3 \pm 1.5$ \\
Co-morbidity \% & 21.6 & 18.6 \\
\hline
\end{tabular}

*: data are presented as mean $\pm \mathrm{SD}$; \#: cases and controls were matched on the fact of at least one asthma hospitalization in the previous $2 \mathrm{yrs}$, but differed in terms of the frequency; patients concurrently using medications for other indications (cardiac, including antihypertensives and diuretics, neurological or contraindicated drugs).

\section{Results}

The characteristics of the study subjects are described in table 1 , along with the distribution of other risk factors, namely the frequency of prior asthma hospitalizations and the prevalence of use of nonasthma medications, the latter used as a measure of co-morbidity. Age, gender, and co-morbidity were similarly distributed in cases and controls, whilst the frequency of prior asthma hospitalizations was unequally distributed in cases and controls. These co-factors were initially adjusted for in the analysis, but, since they did not alter the results of the present study in any way, were all excluded from the final analyses. In addition, the matched reanalysis using conditional logistic regression on the 85 matched sets did not change the results, so that results from the unmatched analyses are presented throughout.

The observed profile score ranged 3.3-8.9, with a mean of 5.5. Figure $3 \mathrm{a}-\mathrm{c}$ displays the mean monthly quantity of $\beta$-agonist use for subjects with a profile score of 5 or less $(n=75)$; between $5-6(n=184)$; and 6 or more $(n=96)$ respectively. They clearly demonstrate that these three categories reflect, on average, decreasing, constant and increasing usage of $\beta$-agonists, respectively over time.

The crude odds ratios (OR) in table 2 indicate increased risks of fatal and near-fatal asthma for users of two or more inhalers of $\beta$-agonist per month $(\mathrm{OR}=2.3 ; 95 \% \mathrm{CI}$ 1.4-3.7), of oral corticosteroids ( $\mathrm{OR}=2.0$; 95\% CI 1.3-3.3), and for subjects with profile scores over $6.5(\mathrm{OR}=4.1$; 95\% CI 1.7-9.9). They also display lower rates for users of one or more canisters of inhaled beclomethasone per month $(\mathrm{OR}=0.2$; 95\% CI $0.1-0.7)$, as has been reported previously [10]. The corresponding adjusted odds ratios, controlling for the other factors in table 2, for users of two or more inhalers of $\beta$-agonists per month $(\mathrm{OR}=2.6$; $95 \%$ CI 1.5-4.4), and for subjects with higher profile scores $(\mathrm{OR}=3.5$; 95\% CI 1.4-8.9), do not indicate much change from the crude estimates. An exception is the lack of risk in the central category of the profile score (score 5-6; OR=1.0; 95\% CI 0.5-2.1), corresponding to constant regular use (as in figure $3 \mathrm{~b}$ ). Consequently, the overall risk associated with the profile score appears to be concentrated mostly in the higher values above 6 , and specifically above 6.5 , corresponding to increasing use. a)

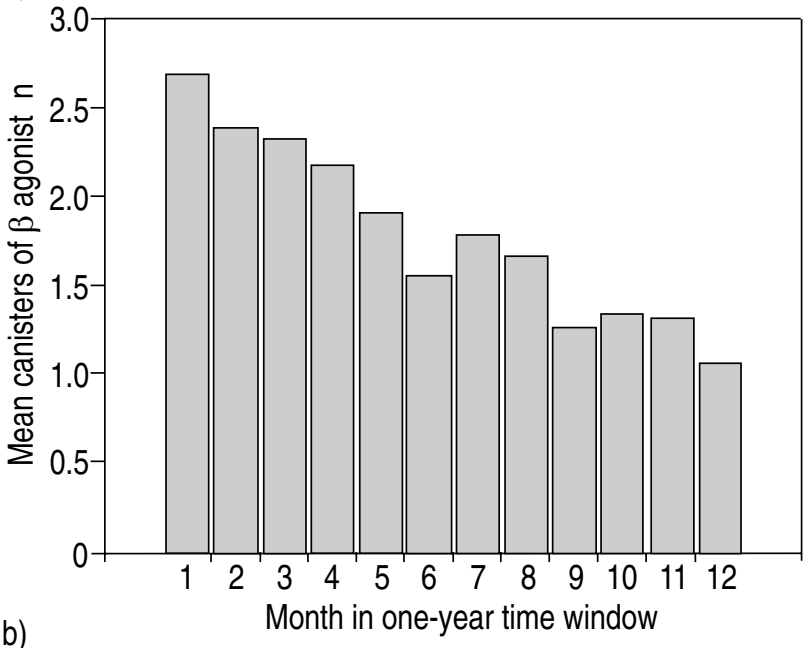

b)

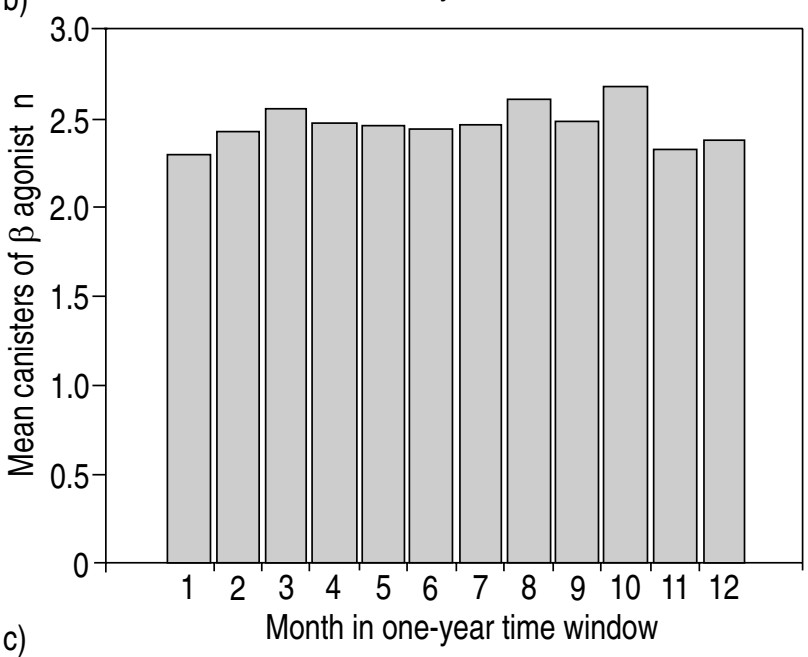

c)

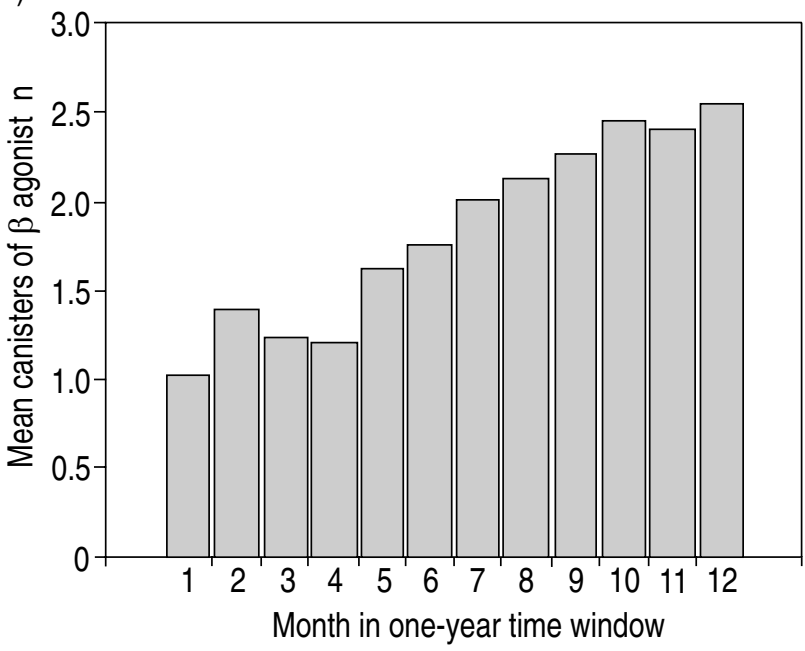

Fig. 3. - Average monthly quantity of $\beta$-agonist use for study subjects with profile scores of: a) 5 or less; b) between 5 and 6 ; and c) 6 or more.

These analyses were redone separately for salbutamol and fenoterol. Figure 4 displays the group with a profile score of 6 or more (increasing use), previously shown in figure $3 c$, separately for the two drugs. The patterns for the two drugs are similar to each other and to that 
Table 2. - Crude and adjusted odds ratios for drug exposures and profile score classified in categories

\begin{tabular}{|c|c|c|c|c|c|c|}
\hline \multirow{2}{*}{\multicolumn{2}{|c|}{ Cases }} & \multirow{2}{*}{$\begin{array}{c}\text { Controls } \\
\mathrm{n}\end{array}$} & \multicolumn{2}{|c|}{ Crude } & \multicolumn{2}{|c|}{ Adjusted* } \\
\hline & & & OR & $95 \% \mathrm{CI}$ & OR & $95 \% \mathrm{CI}$ \\
\hline \multicolumn{7}{|c|}{ Inhaled $\beta$-agonists (MDIs per year) ${ }^{\dagger}$} \\
\hline $12-23$ & 40 & 159 & 1.0 & ref. & 1.0 & ref. \\
\hline$\geq 24$ & 57 & 99 & 2.3 & $1.4-3.7$ & 2.6 & $1.5-4.4$ \\
\hline \multicolumn{7}{|c|}{ Profile score } \\
\hline$\leq 5$ & 14 & 61 & 1.0 & ref. & 1.0 & ref. \\
\hline $5-6$ & 47 & 137 & 1.5 & $0.8-2.9$ & 1.0 & $0.5-2.1$ \\
\hline $6-6.5$ & 19 & 42 & 2.0 & $0.9-4.4$ & 1.7 & $0.7-3.9$ \\
\hline$\geq 6.5$ & 17 & 18 & 4.1 & $1.7-9.9$ & 3.5 & $1.4-8.9$ \\
\hline \multicolumn{7}{|c|}{ Oral corticosteroids } \\
\hline No & 44 & 162 & 1.0 & ref. & 1.0 & ref. \\
\hline Yes & 53 & 96 & 2.0 & $1.3-3.3$ & 2.0 & $1.2-3.4$ \\
\hline \multicolumn{7}{|c|}{ Inhaled corticosteroids (MDIs per year) } \\
\hline$<12$ & 95 & 228 & 1.0 & ref. & 1.0 & ref. \\
\hline$\geq 12$ & 2 & 30 & 0.2 & $0.1-0.7$ & 0.2 & $0.1-0.8$ \\
\hline
\end{tabular}

*: adjusted for all factors in table; $*$ all subjects used 12 or more canisters in the year. OR: odds ratio; 95\% CI: 95\% confidence interval; MDI: metered-dose inhaler; ref: reference category.

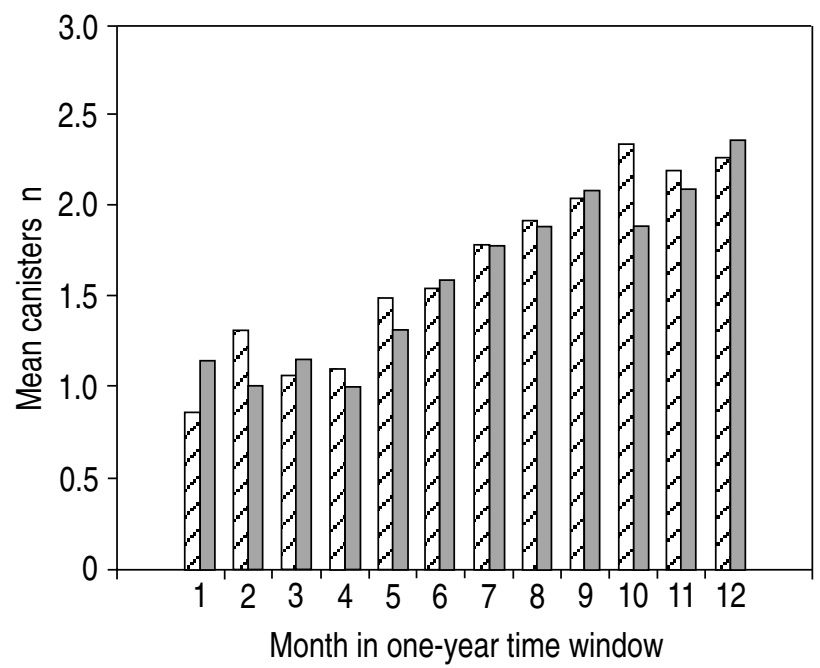

Fig. 4. - Average monthly quantity of $\beta$-agonist use for study subjects with profile scores of 6 or more (increasing profile) according to salbutamol ( $\square$ ) and fenoterol $(\square)$. of all inhaled $\beta$-agonists combined. The results of the regression analyses, presented in table 3 separately for the two drugs, are both similar to those of table 2, indicating the validity of the combined results focusing on the entire class of inhaled $\beta$-agonists.

To improve precision, table 4 displays the results of a logistic regression analysis involving inhaled $\beta$-agonist use and the profile score, both measured on a continuous scale. In particular, to reflect the shape of the risk for the profile score suggested by table 2 , which is essentially flat for lower scores but increasing for upper scores, we used a change-point model for the profile score. This model is made up of two logistic regression models, one model for each of the lower and upper ranges of the profile score, with the profile score specified on a continuous scale and the quantity of inhaled $\beta$-agonist use as the only significant co-factor. This model allows us to estimate the optimal change-point in the range of the profile score, i.e. the value where the risk starts to increase. The resulting change-point from this model is estimated to occur at a profile score of 6.5 . The crude odds ratio for the quantity of inhaled $\beta$-agonist use indicates an increase in risk of 1.5 (95\% CI 1.3-1.9) per inhaler of $\beta$-agonist per month. For the profile score, it is 1.7 (95\% CI 1.0-2.8) per unit in the subjects with a profile score less than 6.5, but it is 14.2 (95\% CI 2.4-83.9) per unit of the profile score for all subjects with a value of 6.5 or more of the profile score. The corresponding adjusted odds ratios are $1.6(95 \%$ CI 1.3-2.0) per inhaler of $\beta$-agonist per month, 1.5 (95\% CI: 0.8-2.6) per unit in the subjects with a profile score less than 6.5 , and 15.2 (95\% CI 2.4-96.2) per unit of the profile score for all subjects with a value of 6.5 or more of the profile score. Figure 5 displays this logistic regression changepoint model along with corresponding estimates based on six categories of the profile score. Although the curve in the upper range of the score appears to be estimated only from two points, this is only for the purpose of illustration. The estimation is in fact based on 59 subjects with an elevated profile score.

This curve permits an assessment of the risk, particularly for patients with increasing use over time. For example, the subject of Figure 1c, with a profile score of 7.5 clearly reflecting increasing use, has a risk 23 times as large as the subject of figure $1 b$, with a score

Table 3. - Crude and adjusted odds ratio for drug exposures and profile score classified in categories

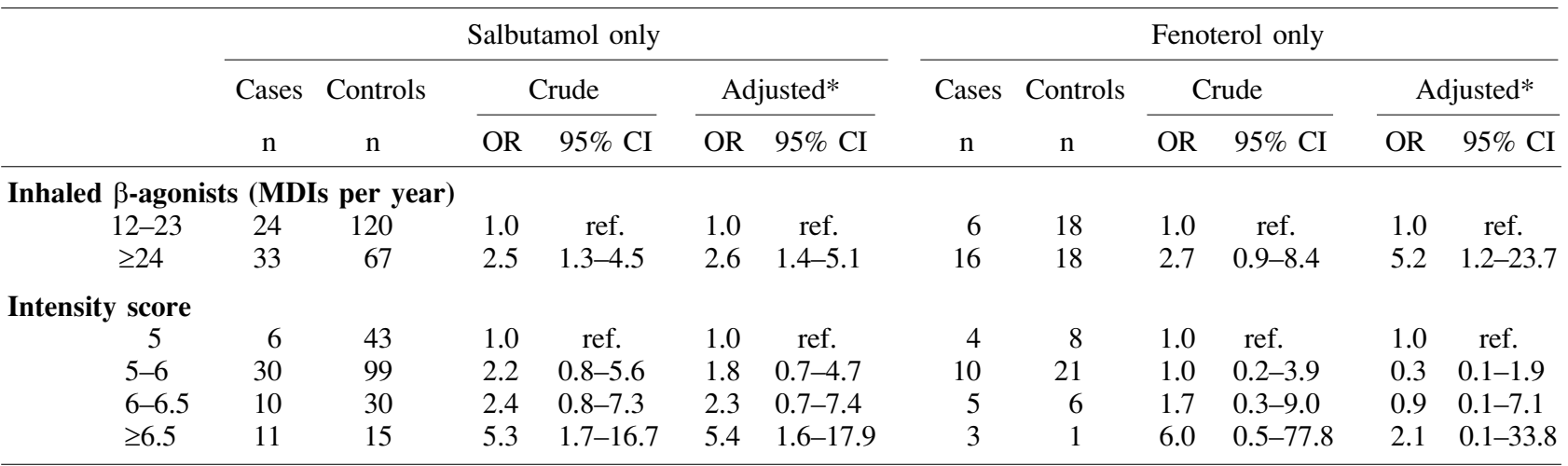

\footnotetext{
*: adjusted for each other, oral corticosteroids and inhaled corticosteroids. For further abbreviations see legend to table 2.
} 
Table 4. - Crude and adjusted odds ratios using continuous measurement for inhaled $\beta$-agonists and profile score by a logistic regression change-point model

\begin{tabular}{lcc}
\hline & \multicolumn{2}{c}{ Odds ratio $(95 \%$ CI) } \\
& Crude & Adjusted* \\
\hline Inhaled $\beta$-agonists $^{\dagger}$ & $1.5(1.3-1.9)$ & $1.6(1.3-2.0)$ \\
Profile score $^{\dagger \dagger}$ & & \\
For subjects with PS $\leq 6.5^{* *}$ & $1.7(1.0-2.8)$ & $1.5(0.8-2.6)$ \\
For subjects with PS $>6.5^{* *}$ & $14.2(2.4-84.0)$ & $15.2(2.4-96.2)$ \\
\hline
\end{tabular}

95\% CI: 95\% confidence interval; PS: profile score. *: adjusted for each other as well as oral and inhaled corticosteroid use. Corresponding odds ratio: ${ }^{\dagger}$ : per canister per month; t* per unit of the profile score (ranges 3.3-6.5 and 6.5-8.9). $* *$ : 6.5 is the estimated change-point.

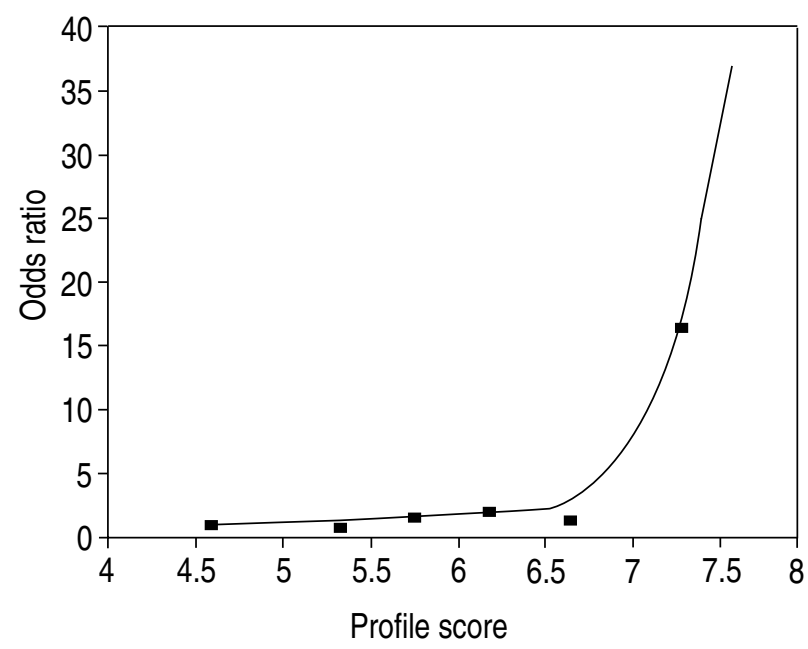

Fig. 5. - Observed and fitted odds-ratio curve as a function of the profile score, from a change-point logistic regression model.

of 5.5 reflecting constant use, although both used identical numbers of canisters during the year, namely 28 , for an average of two and one-third per month. On the other hand, the subject of figure $1 \mathrm{~b}$, with a profile score of 5.5, has a risk only 1.6 times (not statistically significant) as large as the subject of figure $1 \mathrm{a}$, who has a score of 4.3 , which reflects decreasing $\beta$-agonist use over time. Incidentally, these three subjects have a risk 1.6 times as large as that of similar patients using a total of only 16 canisters during the year (i.e. one less canister per month).

\section{Discussion}

In the present report, we found that the pattern of use of inhaled $\beta$-agonists by MDI is associated with the occurrence of fatal or near-fatal asthma. In particular, the increasing frequency of use over time as an asthmatic may approach the adverse event is strongly associated with an increased risk of these adverse events. This study, by its methods and results, highlights three principal points.

The first important result of this study is that the risk associated with a pattern of increasing use appears to be independent of the risk we previously reported with the quantity of $\beta$-agonist use in the year prior to the index event. Indeed, when adjusted for each other, the risks associated with the quantity of $\beta$-agonist use and with the increasing pattern of use remain basically the same. Thus, the pattern of increasing $\beta$-agonist use over time is an additional independent predictor of fatal or near-fatal asthma, over and above the overall quantity of use.

A second feature of this study is that it provides some novelty in epidemiological methods of exposure classification. The most common approach of considering exposure (to $\beta$-agonists in our case) in epidemiological research is as a dichotomy, usually in terms of exposed and unexposed. This classification was used, for example, in all three New Zealand studies [5-7] of the risk of fenoterol. An improvement to this formulation is to quantify exposure in terms of dose or quantity. This strategy was used in our original report [8], and was in fact instrumental in demonstrating the common effect of the entire class of $\beta$-agonists, and not only of fenoterol, when dose and quantity were taken into consideration, as well as in the elaboration of dose-response risk curves [11]. In the current paper, we show that beyond quantity or dose as exposure measures, time patterns of drug use also contain valuable additional information about risk. As depicted in figures $1 \mathrm{a}-\mathrm{c}$, three subjects in our study who have a virtually identical total number of canisters for the one year period, i.e. 27, 28 and 28, have very distinct patterns of use over time and also, according to the results of this study, very different risks. To permit this type of analysis, however, the nested casecontrol study population had to be restricted to patients using sufficient amounts of $\beta$-agonist, which could possibly lead to selection bias. By defining this limit at 12 or more canisters of $\beta$-agonist in a year, we restricted the analysis to 355 patients. This elimination of the 429 low and nonusers (out of 784 subjects), for practical reasons of data analysis, did not lead to a selection bias of the study population, as our previous results were not significantly modified. Indeed, the relative risk of 1.6 per canister per month (95\% CI 1.3-2.0) is near the estimate of 1.9 (95\% CI 1.6-2.4) previously reported with all 784 subjects [8].

Finally, the third point which this study highlights is that increasing patterns of $\beta$-agonist use are much more informative about risks than the quantity of $\beta$-agonist use alone. The previously reported relative risk of 1.9 per additional canister per month [8] suggested that an asthmatic with a profile of $\beta$-agonist use initially set at one canister per month, and gradually increasing to three canisters per month (for an average of 1.75 canisters per month) would increase his/her risk by 3.6. However, from the present study, as depicted in table 5, we estimate that the patient who increases from one to three canisters with a corresponding profile score of 7.4 $(\mathrm{RR}=24.4)$, when compared to a patient regularly using 1.75 canisters per month $(\mathrm{RR}=1.4)$, would have a relative risk of more than $17(=24.4 / 1.4)$, which is much higher than the previously assumed relative risk of 3.6. Moreover, when the former patient is compared to a 
Table 5. - Relative risk estimates for various asthmatics with different patterns of inhaled $\beta$-agonist use over 12 months

\begin{tabular}{ccccc}
\hline $\begin{array}{c}\text { Total } \\
\text { canisters } \\
\text { during year } \\
\mathrm{n}\end{array}$ & $\begin{array}{c}\text { Average } \\
\text { canisters per } \\
\text { month } \\
\mathrm{n}\end{array}$ & $\begin{array}{c}\text { Canisters in } \\
\text { first month } \\
\mathrm{n}\end{array}$ & $\begin{array}{c}\text { Canisters in } \\
\text { last month } \\
\mathrm{n}\end{array}$ & $\mathrm{RR}$ \\
\hline 21 & 1.75 & 1 & 3 & 24.4 \\
36 & 3 & 3 & 3 & 2.6 \\
24 & 2 & 2 & 2 & 1.6 \\
21 & 1.75 & 1.75 & 1.75 & 1.4 \\
12 & 1 & 1 & 1 & $1.0^{*}$ \\
\hline
\end{tabular}

RR: relative risk. *: the reference pattern.

patient whose $\beta$-agonist use is initially one canister per month and remains at one canister per month for an entire year, the relative risk is over 24 . In comparison, even the patient regularly using 3 canisters per month every month for a year (36 canisters for the year) has a relative risk of only 2.6 , when compared to the latter patient who uses exactly one canister per month every month. For the patient regularly using two canisters per month every month for a year ( 24 canisters for the year), this relative risk is 1.6. These scenarios clearly demonstrate that the risk associated with increasing use of inhaled $\beta$ agonists within an individual patient is much more important than the previously computed risk based on different patients. Thus, from its magnitude, the risk specifically associated with increasing use of inhaled $\beta$ agonists within an individual patient during a one year period appears to be much more significant than the risk associated with generally higher use during the year among different patients.

The most straightforward explanation for our results is that the increasing pattern of dispensing is simply reflecting the increasing need for a bronchodilator by a patient whose condition is deteriorating. Accordingly, these results provide a previously unavailable objective verification of this important clinical sign $[12,13]$. This rising pattern of use was present in more than a third (36 of 97 patients) of patients who experienced a fatal or near-fatal attack of asthma, and was particularly pronounced in 17 of those 36 patients. The question of whether the drugs or asthma severity are responsible for these risks still cannot be inferred from these data. However, this study now appears to move the pendulum back to the "severity hypothesis" - that the heavier use of $\beta$-agonists is principally a marker of greater disease severity, which itself is associated with an increased risk of fatal or near-fatal asthma - and militates against the " $\beta$-agonist hypothesis" - that the drugs are causing these adverse effects, independently of disease severity, as we suggested in a previous paper [14]. In the analysis used in this previous paper [14], the attempt to adjust for clinical markers of disease severity was based only on static markers obtained during specific hospitalizations or physician visits. It appears from the current study that markers not of disease severity but of increasing disease severity may have been more pertinent and accurate, and would be necessary to consider in future investigations.
The patterns of increasing use were similar for both salbutamol and fenoterol. The excess risk associated with increasing use also appeared to be similar for these two bronchodilators, though the small number of fenoterol users considerably reduced the power of these analyses. The similarity of risks is compatible with the most likely mechanism for the adverse effects associated with excess beta-agonist use, that over-dependence on such medications, especially if at the expense of effective antiinflammatory therapy, is accompanied by progressive worsening of disease severity and ultimately increased risk of acute asphyxia attacks. This is supported by the findings of Molfino et al. [15] in cases of near-fatal asthma.

The risk associated with higher use of inhaled $\beta$ agonists reported in our previous study [8] received considerable attention. This finding contributed to setting in motion various recommendations for the management of patients who were discovered to use excessive amounts of inhaled $\beta$-agonists $[16,17]$. Similarly, in the present study, the elevated risks associated with increasing use of inhaled $\beta$-agonists over time strongly suggest the implementation of additional mechanisms to monitor this use at regular time intervals and to detect potentially harmful increasing trends. These mechanisms may prove to be more valuable than those based on total $\beta$-agonist use during an entire year. From the data of figure $3 c$, restricted to subjects with a profile score of 6.5 or more, the trends suggest that a doubling in the monthly number of $\beta$-agonist canisters over a six month period is a signal of major imminent risk.

Alternatively, an increase of one canister per month over a six month period is an equivalent warning sign. Thus, for example, if a patient increases his/her use from one-half canister per month to one per month over a six month period span (doubling), or from 1.5 canisters per month to 2.5 per month over 6 months (one additional canister), one should consider these as serious warning signs of an impending life-threatening attack of asthma.

\section{References}

1. Speizer FE, Doll R. A century of asthma deaths in young people. Br Med J 1968; 3: 245-246.

2. Inman WHW, Adelstein AM. Rise and fall of asthma mortality in England and Wales in relation to use of pressurized aerosols. Lancet 1969; ii: 279-285.

3. Gandevia B. The changing pattern of mortality from asthma in Australia. Med J Aust 1968; 1: 747-752 and 884-891.

4. Stolley P. Asthma mortality: why the United States was spared an epidemic of deaths due to asthma. Am Rev Respir Dis 1972; 105: 883-890.

5. Crane J, Pearce N, Flatt A, et al. Prescribed fenoterol and death from asthma in New Zealand 1981-1983: casecontrol study. Lancet 1989; i: 917-922.

6. Pearce N, Grainger J, Atkinson M, et al. Case-control study of prescribed fenoterol and death from asthma in New Zealand, 1977-1981. Thorax 1990; 45: 170-175.

7. Grainger J, Woodman K, Pearce N, et al. Prescribed fenoterol and death from asthma in New Zealand, 1981-1987. Thorax 1991; 46: 105-111. 
8. Spitzer WO, Suissa S, Ernst P, et al. The use of $\beta$ agonists and the risk of death and near-death from asthma. N Engl J Med 1992; 326: 501-506.

9. Rea HH, Scragg R, Jackson R, Beaglehole R, Fenwich J, Sutherland DC. A case-control study of deaths from asthma. Thorax 1986; 41: 833-839.

10. Ernst P, Spitzer WO, Suissa S, et al. Risk of fatal or near-fatal asthma in relation to inhaled corticosteroid use. J Am Med Assoc 1992; 268 (24): 3462-3464.

11. Suissa S, Ernst P, Boivin JF, et al. A cohort analysis of excess mortality in asthma and the use of inhaled $\beta$ agonists. Am J Respir Crit Care Med 1994; 149: 604 610.
12. Woolcock AJ. Asthma. In: Murray JF, Nadel JA, eds. Textbook of Respiratory Medicine. Philadelphia, W.B. Saunders Co., 1988; pp. 1030-1068.

13. Burrows B, Lebowitz MD. The $\beta$-agonist dilemma. $N$ Engl J Med 1992; 326: 560-561.

14. Ernst P, Habbick B, Suissa S, et al. Is the association between inhaled $\beta$-agonist use and life-threatening asthma because of confounding by severity? Am Rev Respir Dis 1993; 148: 75-79.

16. International consensus report on diagnosis and treatment of asthma. Eur Respir J 1992; 5: 601-641.

17. British Thoracic Society. Guidelines on the management of asthma. Thorax 1993; 48 (Suppl.): 1-24. 